\title{
Mapping and enumerating houses and households to support malaria control interventions on Bioko Island
}

\author{
Guillermo A. García ${ }^{*}$ (D), Dianna E. B. Hergott ${ }^{2}$, Wonder P. Phiri ${ }^{3}$, Megan Perry ${ }^{1}$, Jordan Smith³, \\ Jose Osa Osa Nfumu ${ }^{3}$, Jeremías Nzamio ${ }^{3}$, Godwin Fuseini ${ }^{3}$, Thomas Stabler ${ }^{4}$, Matilde Riloha Rivas ${ }^{5}$, \\ Immo Kleinschmidt ${ }^{6}$, Christopher Schwabe ${ }^{7}$ and Carlos A. Guerra ${ }^{1}$
}

\begin{abstract}
Background: Housing mapping and household enumeration are essential for the planning, implementation, targeting, and monitoring of malaria control interventions. In many malaria endemic countries, control efforts are hindered by incomplete or non-existent housing cartography and household enumeration. This paper describes the development of a comprehensive mapping and enumeration system to support the Bioko Island Malaria Control Project (BIMCP).

Results: A highly detailed database was developed to include every housing unit on Bioko Island and uniquely enumerate the associated households residing in these houses. First, the island was divided into a virtual, geo-dereferenced grid of $1 \times 1 \mathrm{~km}$ sequentially numbered map-areas, each of which was in turn subdivided into one hundred, $100 \times 100$ m sequentially numbered map-sectors. Second, high-resolution satellite imagery was used to sequentially and uniquely identify all housing units within each map-sector. Third, where satellite imagery was not available, global positioning systems (GPS) were used as the basis for uniquely identifying and mapping housing units in a sequential manner. A total of 97,048 housing units were mapped by $2018,56 \%$ of which were concentrated in just $5.2 \%$ of Bioko Island's total mapped area. Of these housing units, $70.7 \%$ were occupied, thus representing uniquely identified households.

Conclusions: The housing unit mapping and household enumeration system developed for Bioko Island enabled the BIMCP to more effectively plan, implement, target, and monitor malaria control interventions. Since 2014, the BIMCP has used the unique household identifiers to monitor all household-level interventions, including indoor residual spraying, long-lasting insecticide-treated nets distribution, and annual malaria indicator surveys. The coding system used to create the unique housing unit and household identifiers is highly intuitive and allows quick location of any house within the grid without a GPS. Its flexibility has permitted the BIMCP to easily take into account the rapid and substantial changes in housing infrastructure. Importantly, by utilizing this coding system, an unprecedented quantity and diversity of detailed, geo-referenced demographic and health data have been assembled that have proved highly relevant for informing decision-making both for malaria control and potentially for the wider public health agenda on Bioko Island.
\end{abstract}

Keywords: Malaria, Household, Housing, Enumeration, Control interventions, Bioko Island

\footnotetext{
*Correspondence: ggarcia@mcd.org

${ }^{1}$ Medical Care Development International, Silver Spring, MD, USA

Full list of author information is available at the end of the article
} 


\section{Background}

Bioko Island is located in the Bight of Biafra, off the coast of Cameroon, and is the largest and most important island of Equatorial Guinea. Bioko Island has an area of approximately $2000 \mathrm{~km}^{2}$ and a population of about 250,000 inhabitants, $80 \%$ of whom live in the main city, Malabo, which is also the country capital. The Bioko Island Malaria Control Project (BIMCP) was established in 2003 as part of the National Malaria Control Programme (NMCP) of the Ministry of Health and Social Welfare of Equatorial Guinea to implement malaria control interventions with the aim of reducing the burden of, and ultimately eliminating, the disease on the island [1-5].

In 2018, the BIMCP completed its third 5-year phase, having achieved significant reductions in malaria transmission as measured by parasite prevalence, fever cases, anemia and all-cause mortality in young children [3, 6 , 7]. The success also is reflected in entomological indicators, with significant reductions in anopheline human biting rates [8], sporozoite rates, and vector density [9]. Recent analyses strongly suggest that autochthonous transmission may have been interrupted in many areas of the island and that observed prevalence could be largely attributed to importation [10]. Behind these successful outcomes are years of funding that assured the scale-up of malaria interventions, including 10 years of extensive and intensive indoor residual spraying (IRS) followed by 5 years of targeted focal spraying, several mass distribution and hang-up campaigns for long-lasting insecticide-treated nets (LLINs) sustained by continuous distribution through antenatal clinics and intermittent primary-school campaigns, focal targeted larval source management, universally free malaria diagnosis and treatment, and intermittent preventive therapy for pregnant women. This high coverage of interventions has been monitored through entomological surveillance, annual malaria indicator surveys (MIS), and a health information system based on individual patient records $[11,12]$.

Effective resource allocation for malaria control depends on accurate denominators that define and fully characterize the relevant intervention universe [13]. Among the challenges faced by the BIMCP during the initial phase of the project was the limitation of operating without detailed housing unit cartography and household enumeration to support effective planning and implementation of interventions. Households were counted within communities of which there was limited spatial knowledge. The absence of a geo-referenced households database thus translated into uncertain and inaccurate knowledge of the true denominator of units for intervention and, therefore, into sub-optimal planning, targeting and coverage monitoring [1]. The impact of these limitations was further exacerbated by the rapid growth in housing stock associated with the booming oil-driven economy, including substantial growth in informal urban housing in Malabo.

Accurate household enumeration, therefore, is key for the implementation of household-based interventions. Moreover, there is an increasing need for scalingup or adapting malaria control and much of this can be informed by wide-scale household surveys [14]. Notwithstanding, for many malaria control programmes, enumeration methods remain rudimentary or nonexistent and relatively little effort seems to have been invested in instituting mapping and enumeration systems as part of malaria control programmes. Recently, new methodologies have been tested driven by the need to reassess vector control strategies towards more targeted approaches in sub-Saharan malaria endemic areas [15, 16]. In Mozambique, houses in Mopeia district were enumerated by the use of GPS and satellite imagery triangulation; satellite images allowed the identification of areas that had been missed in the first round of enumeration that later were revisited for inclusion. In Zambia, opensource satellite imagery was used for household enumeration in 15 districts and proposed as a more efficient alternative to field enumeration methods. This methodology was tested in rural areas where housing density was low and atmospheric conditions proved favourable (i.e. limited cloud cover), and was used later for targeting IRS activities [17].

This paper describes the experience developing a cartographic system to map housing units and enumerate households on Bioko Island and how it has enabled the BIMCP to substantially improve its planning, service targeting, impact and coverage monitoring, to enhance the effectiveness of its interventions and to ultimately achieve a continued reduction of malaria burden on the island. The system was developed with the approval and collaboration of the NMCP. For clarity, the paper refers to buildings destined for human habitation as houses or housing units, and as households to groups of people that reside in a housing unit and who regularly share meals together. Therefore, housing units may be occupied (have a resident household) or unoccupied (have no resident household).

\section{Methods}

The process of mapping housing units and enumerating households was initiated on a pilot basis in one community in 2011, extended to 18 sentinel sites [2] later in the same year, and systematically implemented on the whole island by 2014. Bespoke application software was used to support enumeration and data entry in the 
field, at first with the use of electronic personal digital assistants (PDAs) and later through the use of tablet computers. The methodology involved developing

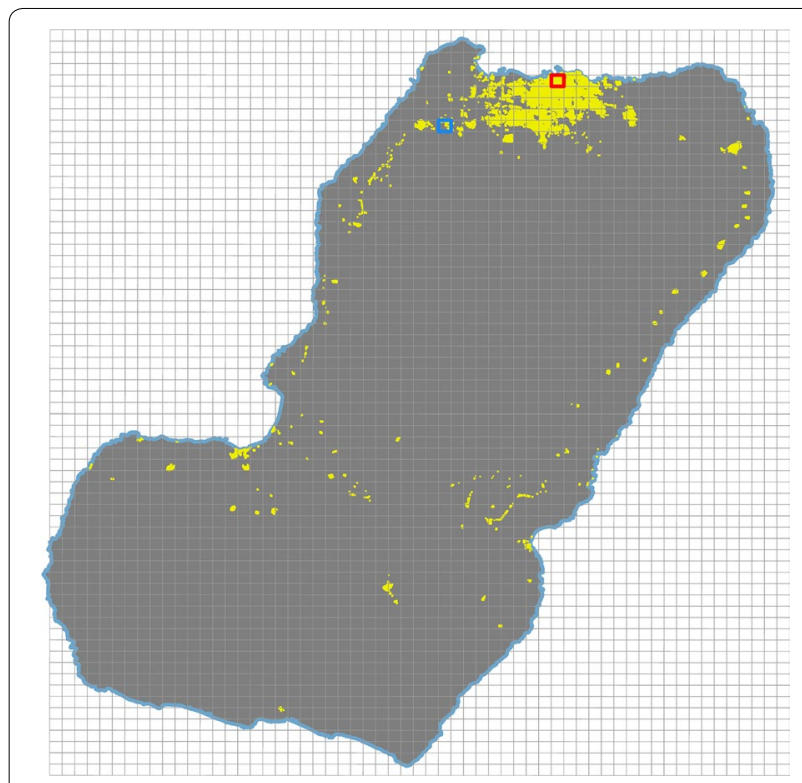

Fig. 1 The mapping and coding system for Bioko. A virtual grid of $1 \times 1 \mathrm{~km}$ map-areas (grey lines) was used to generate unique identifiers. Example map-areas M0277 (urban) and M0504 (rural) are highlighted with red and blue boxes, respectively. The yellow dots represent housing units in 2018; grey areas are uninhabited a consistent coding system for uniquely identifying and mapping housing units with the aid of remote sensing imagery and global positioning systems (GPS), as well as geo-referencing them through an interaction between teams collecting data in the field (i.e. ground truth of locations) and data analysts assembling the information on a geographical information system (GIS). The ultimate aim of this process was to have a complete geographical database of housing units, each assigned a unique identifier and linked to several attributes, including housing occupancy and household information. This methodology is described in more detail below.

\section{A system for uniquely identifying housing units}

A coding system was established by first creating a virtual, rectangular, geo-referenced grid of 59 by $661 \times 1 \mathrm{~km}$ cells on a GIS that covered the whole territory of Bioko Island (Fig. 1). These cells, referred to as map-areas, were sequentially numbered from left to right and top to bottom, that is from cell 0001, at the top left, to cell 3894, at the bottom right of the grid. Another grid divided each map-area into one hundred, $100 \times 100 \mathrm{~m}$ cells, referred to as map-sectors (Fig. 2). Map-sectors were numbered within each map-area in the same way, from left to right and top to bottom, from cell 001 to cell 100 .

Unique identifiers for each map-area and each mapsector were represented by their number preceded by a letter $\mathrm{M}$, for map-area, and a letter $\mathrm{S}$, for map-sector.

\section{a}

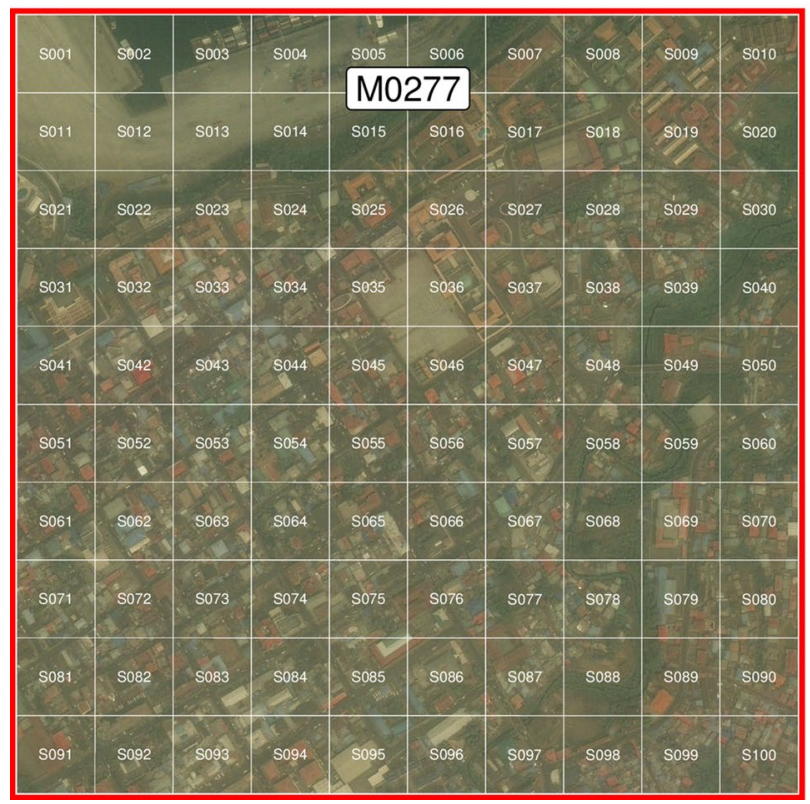

b

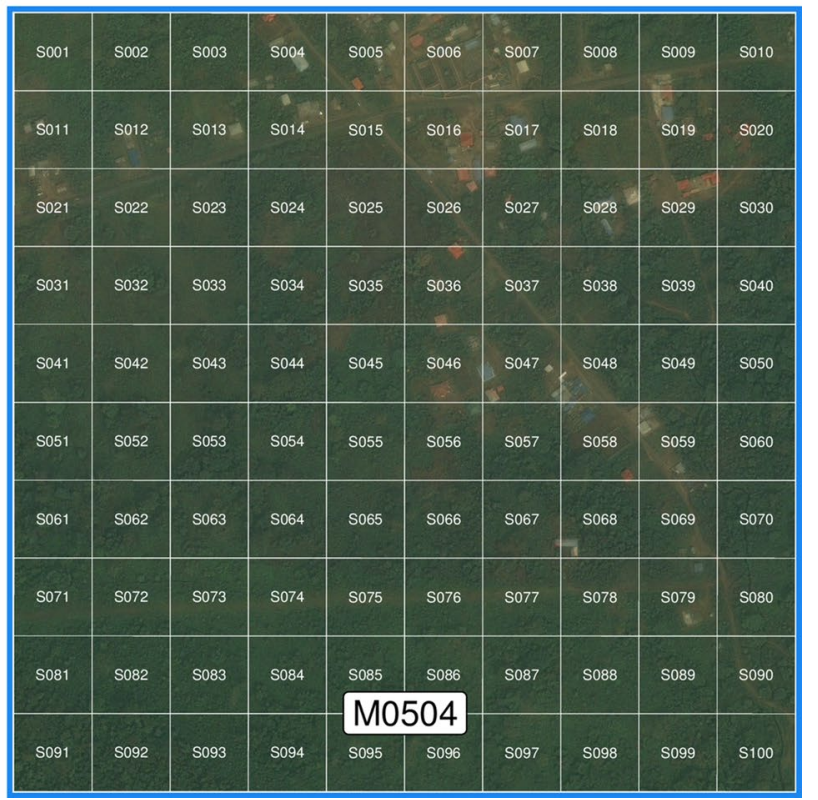

Fig. 2 Detail of map-areas M0277 (urban) and M0504 (rural). A grid of $100 \times 100$ m map-sectors (white lines) subdivided each map-area into 100 cells. The satellite images shown here were sourced from Digital Globe [18] 
That is, a letter $\mathrm{M}$ followed by four digits (between 0001 and 3894) uniquely identified map-areas and a letter $\mathrm{S}$ and three digits (between 001 and 100) uniquely identified map-sectors. For example, code M0277S080 is the unique identifier for map-sector 080 within map-area 0277 (Fig. 2). Unique identifiers for housing units within map-sectors were assigned using a letter E (in reference to the word "edificio", or building in Spanish) followed by three digits. Hence, the code M0277S080E011 uniquely identifies the 11th housing unit found within sector M0277S080 (Fig. 3). Multiple housing units corresponding to apartments on different floors within the same building were assigned different unique identifiers. In addition, a letter P (standing for "piso", or floor/level in

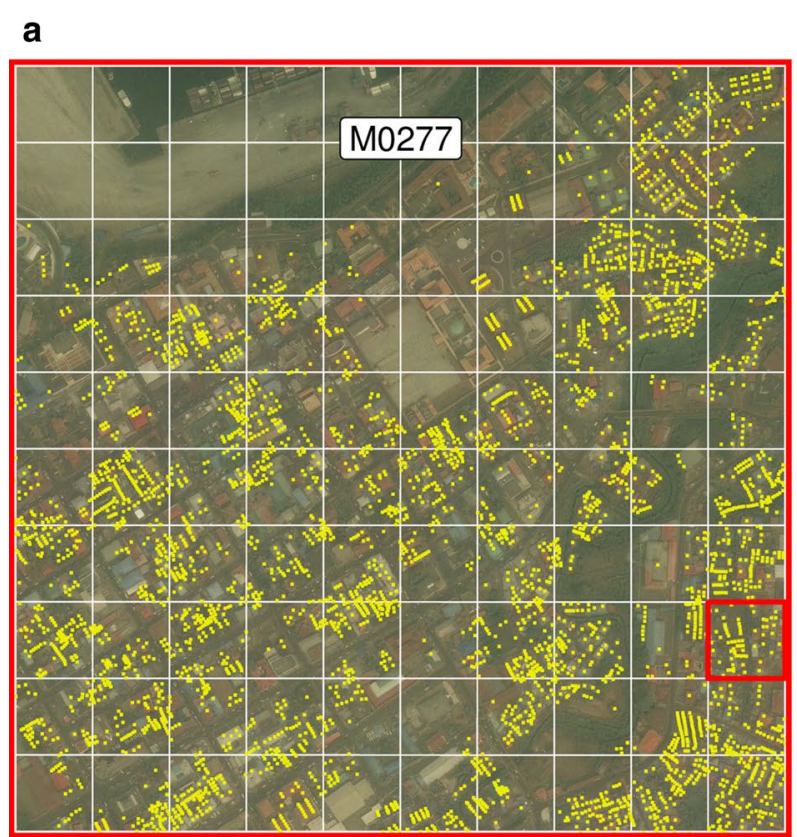

b

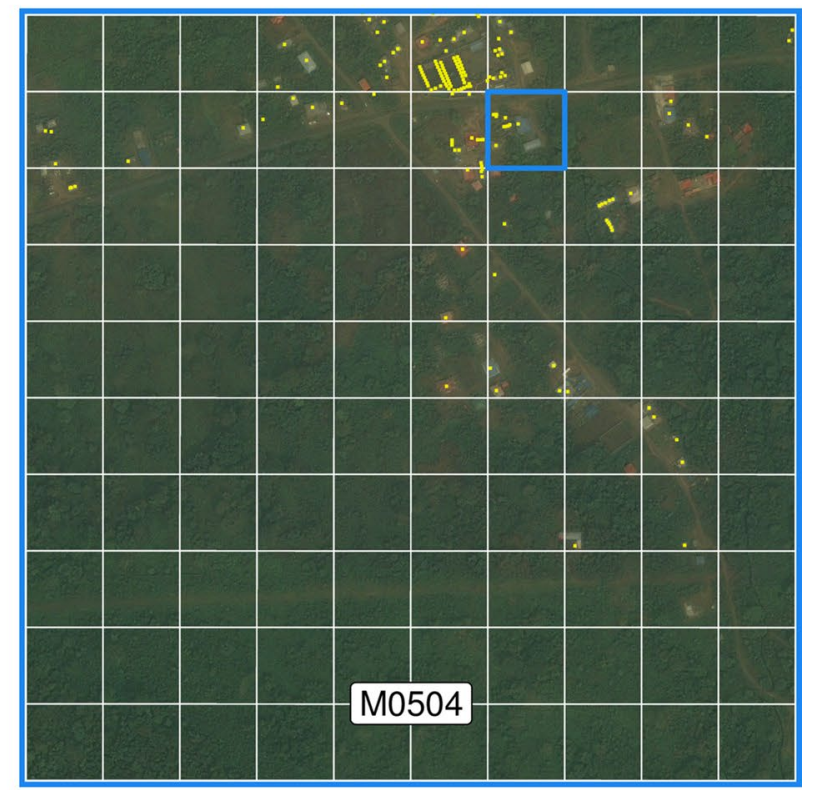

d

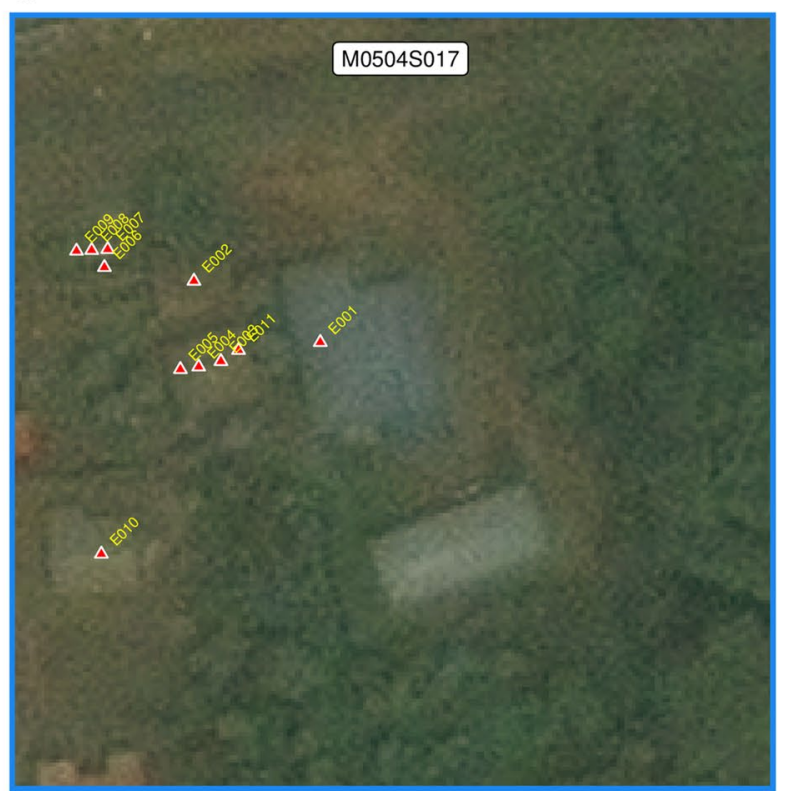

c

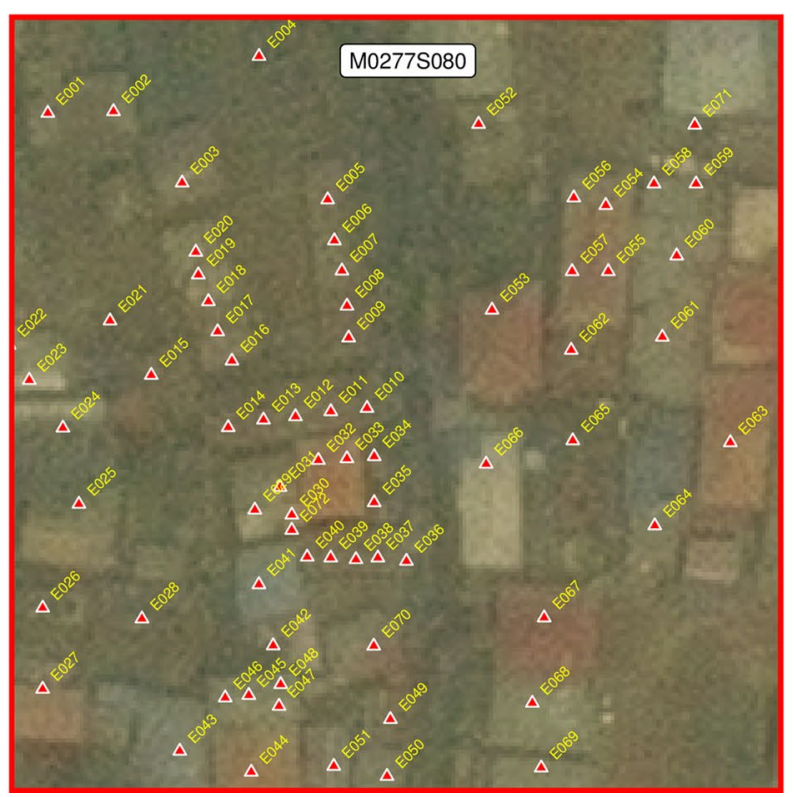

Fig. 3 Location of mapped housing units. a, b Yellow dots illustrate housing units within map-areas M0277 (urban) and M0504 (rural) (Fig. 1).c, d Housing units and their unique identifiers within map-sectors M02775080 and M0504S017 (red and blue boxes in a and b). Note that buildings without unique identifiers do not correspond to housing units. The satellite images shown here were sourced from Digital Globe [18] 
Spanish) followed by two digits defined the floor where the housing unit was located (i.e. using the same example above, the full code for the housing unit, if it were located on the second floor, would be M0277S080E011P02).

\section{Mapping housing units}

High-resolution satellite imagery was available between 2011 and 2014 only for the map-sectors in the Malabo area and surroundings [18]. In these cases, mapping teams were provided with printed maps containing the satellite image and the limits of the map-sector. In map-sectors for which satellite imagery was unavailable, or where such imagery was of a poor resolution or was cloud-obscured, the teams used the map-sector limits overlaid on detailed hand-drawn maps of streets, roads and pathways produced by the BIMCP using GPS, where they drew in buildings, locating these in space relative to these features. This was the case for most of the areas outside of Malabo, including rural and peri-urban areas. However, as updated, extended and improved resolution satellite imagery became progressively available over time, map-sector maps were converted from the GPScoordinate dependent hand-drawn maps to satellitebased maps.

Mapping teams walked each map-sector on a path pre-determined on the printed maps, usually following a "serpentine pattern" starting in one corner and ending in the opposite corner of the map-sector. Mappers drew the outline of each building on the satellite image, or sketched out any new ones that they found. For mapsectors with no satellite imagery, they sketched out the buildings on the printed map and also took GPS readings. All housing units, whether they were occupied by households or not, were numbered sequentially in the order they were found along the predetermined path. In the case of housing units falling on the limits and overlapping two map-sectors, a decision was made to assign them to one or the other. The number for each housing unit (i.e. the three digits that follow the letter $\mathrm{E}$ in the unique identifier) was generated automatically by the PDA/tablet application and this was written down within or near the building outline on the paper map. For each housing unit, additional information was gathered such as a brief description of the house for easier identification in future visits (e.g. physical appearance, nearby landmarks), construction materials (e.g. wood, cement), other housing characteristics (e.g. open eaves, screened windows/doors, air-conditioning units) and, for occupied housing units, the demographics of all household members. A sticker with the unique identifier was affixed to the entrance door of each housing unit.

All printed maps sketched by the field teams were scanned to manually assign geographical coordinates to housing units based on the satellite imagery. For mapareas with no underlying images, the GPS coordinates obtained in the field were used. The geographical coordinates were linked to the data gathered on the PDA/tablet application and this completed the housing unit records.

\section{Results}

By the close of the first phase of the mapping of housing units and enumeration of associated households in $2014,78,524$ housing units had been mapped. Due to the rapid increase in housing infrastructure over time, by mid-2018, 18,524 new housing units had been added to the database to total 97,048 houses within 251 map-areas and 4467 map-sectors (Fig. 1), of which 68,619 (70.7\%) were occupied. This represented an overall increase of $23.6 \%$ in the housing stock since the baseline mapping was completed, or an average $5.9 \%$ increase per annum (Table 1). Figure 3 illustrates mapped housing units in a high population density urban setting and in a low population density rural setting together with their unique identifiers. In these examples, there were 4373 mapped housing units in urban map-area M0277 compared to 164 in rural M0504, and 73 and 11 mapped houses in map-sectors M0277S080 and M0504S017, respectively. Housing density by map-area was highly skewed, ranging from 1 to 6840 housing units, with a median of 52 (Fig. 4). Fifty six percent of mapped housing units were concentrated in only $13(5.2 \%)$ map-areas. The city of Malabo accounted for $83.8 \%$ of all houses on the island, with a median number of housing units per map-area of 707. House density at the map-sector level ranged between 1 and 227, with a median of 10 . Over one quarter $(26 \%)$ of mapped housing units were contained within $5.1 \%$ of map-sectors on Bioko.

Table 2 summarizes the benefits of having a georeferenced housing/household database for implementing key interventions and surveillance on Bioko Island (i.e. IRS, LLIN distribution and annual MIS). These were benefits at the household-level and at the community-level relative to implementation of malaria control activities before the household database was established. Because individual household tagged with

\section{Table 1 Number of mapped housing units, by year}

\begin{tabular}{lll}
\hline Year & \# houses & \% increase \\
\hline 2014 & 78,524 & - \\
2015 & 82,567 & 5.1 \\
2016 & 89,023 & 13.4 \\
2017 & 95,963 & 22.2 \\
2018 & 97,048 & 23.6 \\
\hline
\end{tabular}

The percent of increase is relative to the baseline number in 2014 
a

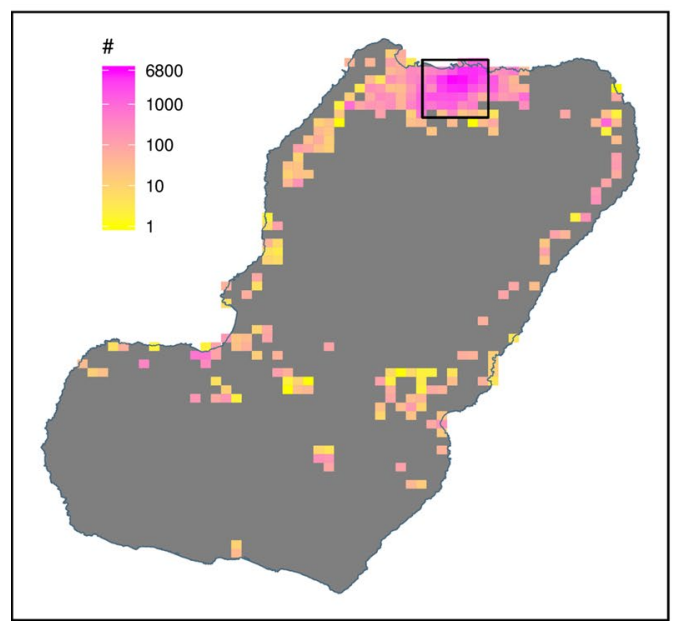

b

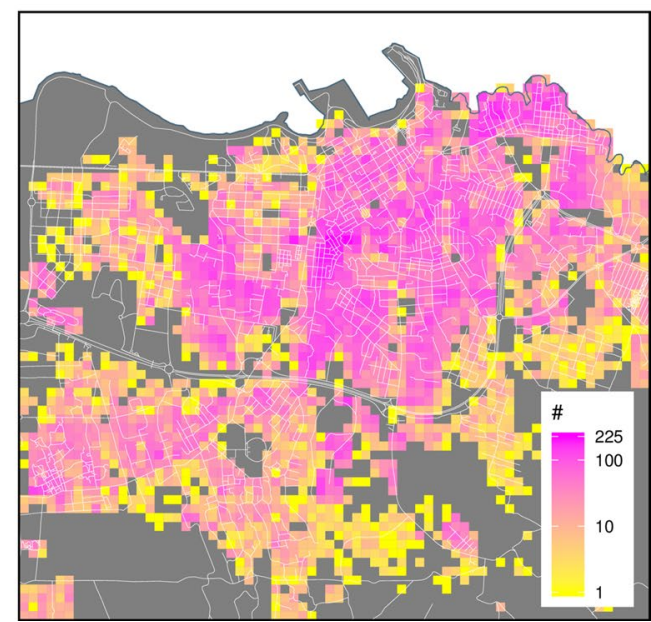

Fig. 4 Housing unit density on Bioko Island. Density is shown by $\mathbf{a}$ map-area and $\mathbf{b}$ map-sector. The black box in a delimits the detail of Malabo shown in $\mathbf{b}$

Table 2 Benefits of a geo-referenced household database for implementing key interventions on Bioko Island

\begin{tabular}{ll}
\hline Intervention & Benefits \\
\hline IRS/LLINs & Household-level \\
Ability to track household interventions longitudinally based on perma- & nent and unique household identifiers (e.g. track intra-household LLIN \\
movement, monitoring insecticide concentrations following spray & rounds) \\
Ability to target households during initial and follow-up rounds of inter- & ventions \\
Ability to verify and track sprayed households & Ability to target interventions based on household-level data \\
& Community-level \\
Ability to adequately quantify insecticide and LLIN requirements & Improved deployment based on geo-political boundaries and known \\
confirmed inhabited households & \\
Improved field supervision of control teams, including control of the true \\
coverage achieved \\
Ability to adequately engage community leaders to support interven- \\
tions, particularly in urban areas \\
Household-level \\
Ability to link surveyed households longitudinally \\
Ability to easily locate and survey pre-selected households \\
Community-level \\
Improved supervision to track and verify surveyed households \\
Ability to estimate malaria prevalence at different spatial scales
\end{tabular}

unique identifiers could be followed-up longitudinally, the programme could verify the continuity of interventions and of survey information. Based on these data, households could be individually targeted during, for example, IRS rounds. At community-level, household information provided the denominators upon which to plan interventions and quantify the resources needed to reach coverage targets. These denominators were also the basis for assessing intervention coverage, something that was not possible before the introduction of the household database.

\section{Discussion}

The mapping and enumeration system developed for Bioko proved to be instrumental support for malaria control interventions on the island. The ability to uniquely identify and locate housing units and households substantially enhanced the planning, managing 
and monitoring of malaria control interventions and the accuracy with which service coverage was measured. Since 2014 this has been done through the Campaign Information Management System (CIMS), an Androidbased application built around the household database and used as a tool for identifying and locating households targeted for interventions and for surveying. The household database provides the denominator for managing interventions, monitoring coverage and setting desired targets, particularly for IRS and LLINs distribution campaigns. Household level interventions can be monitored and followed longitudinally. As such, it is possible to know how many times each house was sprayed, received LLINs and was surveyed within any given time frame. Improved control of intervention teams is achieved when comparing outcomes against known denominators. Moreover, as information is uploaded to the CIMS, realtime monitoring and quality assurance of interventions is possible. All data entered through the CIMS, including current and new housing and household data, are owned by the NMCP. The data are encrypted and hosted on an online server and are accessible only to authorized users.

Demographic and environmental conditions on Bioko Island can limit the application of satellite imagery alone for mapping households, as was proposed by Kamanga and colleagues in their study in Zambia [16]. First, high population density urban areas on Bioko are equally targeted for control but difficult to map using remote sensing images. Second, open-source satellite imagery is usually outdated by between 1 and 3 years and, without complementary field-based validation methods, becomes quickly obsolete in the face of a rapid rate of housing growth like the one observed on Bioko Island. Third, cloud cover over the island can frequently hamper the use of remote sensing data. Finally, in both urban and rural areas of Bioko, many families live under the same roof. This general cultural household configuration is complicated by the fact that in rural areas households are relatively close to each other. It is impossible to tell that several families live under the same roof without field verification of satellite imagery. Hence, the mapping methodology used a hybrid approach that resorted to satellite imagery, GPS mapping and ground verification. In this way, it was possible to optimize the advantages provided by each method whilst overcoming their inherent limitations given by the specific context of Bioko Island. As a result of this exercise, all households on the island have been verified on the ground for accuracy to confirm that they exist, providing high confidence in the household counts.

Mapping housing units and enumerating households was particularly challenging and labor intensive in areas containing thousands of housing units per square kilometre. The system was developed on a learning-bydoing basis that increased the man-power needed to complete the mapping by, for example, assigning teams specifically for this task. One valuable lesson that was learned as the mapping progressed was that the mapping can be done at the same time and by the same personnel carrying out field interventions. This will not only reduce the burden of hours required to complete the mapping but also presents no limitation on how big or small an area can be mapped. It also makes the maintenance and updating of the household database relatively simple and straightforward during field visits by survey, spraying, and net distribution teams. One approach could be to use remote sensing to provide baseline count of buildings in a particular area in order to provide an a priori estimate of the resources needed to undertake household mapping and carry out an intervention. In such a scenario, the field team would verify the pre-identified buildings and then would assign codes to the households identified within those buildings. Regardless of the initial methodology adopted for the baseline mapping, the grid-based coding system allows quick allocation of household codes during visits without necessarily using satellite imagery. Map-areas and map-sectors provide unambiguous, georeferenced boundaries where households can be mapped and coded, even without the use of GPS.

The methodology presented here was appropriate in a context like that of Bioko Island, which is similar to many malaria endemic settings, where urban areas lack a postal code system, so the virtual grids provided a simple, location-based way to assign unique identifiers. Because map-areas, map-sectors and houses are numbered sequentially, it is intuitive to navigate within the grids and locate houses based simply on unique identifiers. This has proven a big advantage particularly in the high-density housing areas of Malabo. In some way, the grid-based system described resembles a similarly innovative, location-based coding system that was recently developed to enumerate households in a densely populated impoverished area of Mumbai, India. Based on a virtual coordinate grid, this system allowed quick location of houses where the utility of GPS and satellite images proved limited [19]. The grid-based coding system also allows for rapid updating as new housing develops and households move between housing units. Because mapping activities have been integrated into all household-based interventions, field teams are trained to update the mapping system in real-time; in this way, new housing units are assigned the next subsequent code available. Given the close to $6 \%$ annual increase in housing infrastructure and the $30 \%$ unoccupancy of housing units on Bioko, which are suggestive of a high household turnover, this proved a particularly valuable feature of the mapping system. 
The grid-based system provides further benefits. Since it was established, all data collected on Bioko Island at the household or individual level can be readily geo-referenced by indexing on the unique household identifier. Data can then be analyzed at various levels of aggregation, from individual, to household, to map-sector, to map-area level. The medical intelligence assembled by the BIMCP has thus reached a high level of sophistication. While the virtual grid system has no relevance from the standpoint of demarcating administrative boundaries, from a scientific and programmatic perspective it has the benefit of allowing analyses to be made within coherent spatial scales unaffected by the potential arbitrariness of political boundaries. For example, the gridbased system was used as the basis for the design of a cluster-randomized trial comparing the effectiveness of insecticides used for IRS in central Malabo [20]. More recently, map-area-based analyses were used to investigate human mobility and malaria prevalence in relation to malaria importation to Bioko [10].

The impact that the mapping system and the household database have had overall on malaria control activities on Bioko Island is wide-ranging (Table 2). The BIMCP has conducted four MIS, five IRS rounds and two LLINs mass distribution campaigns since the household database was established. This has allowed tracking the impact of interventions not only at the household level but also over time. The LLINs mass distribution campaigns of 2015 and 2018 achieved 88\% and 85\% coverage, respectively, and those households who did not receive LLINs, and the reasons for this, were recorded in the database. Pilot studies to assess the quality of LLINs have been possible by randomly selecting households that received nets to check for physical condition and quantify insecticide levels. Similarly, IRS coverage assessment has been possible with a high degree of accuracy and the household database has allowed recording why some houses were not sprayed. Plans are also underway to implement IRS targeting at the map-sector level; this increase in granularity of intervention planning will allow better targeting of transmission hot spots and improved assessment of intervention coverage. The household database also supports quality control of spraying rounds whereby sprayed houses are randomized for wall sample collections to quantify insecticide levels. Because sprayers are linked to the households they sprayed, based on this quality control, sprayers are retrained to improve their skills for subsequent rounds. Entomological surveys have also recently been incorporated to the CIMS to improve on the information derived from entomological monitoring. The household database is useful for recruiting households and individuals for ongoing and future studies. These include a malaria incidence study that is underway in a high prevalence area, as well as future vaccine trials on Bioko Island to assess the efficacy of a malaria vaccine candidate [21].

During the mass LLINs distribution campaigns, two population censuses were conducted that linked individuals to their household identifiers [22, 23] and these have provided a very high spatial resolution rendering of human population distribution on the island. These census data can be aggregated to the map-sector or maparea level for stratified, household sampling as one would do using gridded population surfaces [24]. Importantly, given its high spatial resolution, the map-sector grid is less prone to modifiable area unit problems that are evident when using large spatial units [24]. Therefore, mapareas and map-sectors can be effectively used as primary and secondary sampling units for multi-stage sampling surveys for a number of different purposes [14, 24, 25]. The household database could also provide the infrastructure for establishing a demographic surveillance system on Bioko Island [26]. More work is needed to analyze the extensive data sets assembled by the BIMCP at various spatial scales, to fully utilize the household database and mapping system and to assess their potential for numerous applications beyond malaria control. Though the mapping system was developed specifically to guide malaria control interventions, the household data are planned to support other public health interventions in the future and have already been used to inform poliomyelitis vaccination campaigns. In addition, the household database is being used by other governmental offices for the implementation of household-based surveys of various natures. Moreover, longer-term goals are being considered to expand the mapping system to the rest of the country and to use the data more widely in different public health programmes.

\section{Conclusions}

Housing cartography and household enumeration are fundamental for adequate planning and implementation of household-based public health interventions. The enumeration system presented here is built around an unambiguous coding system and is supported by a software infrastructure that permits updating the household database in real-time. Because the cartographic system itself was developed using a combination of satellite imagery and field enumeration, this methodology is applicable and adaptable to a wide range of settings. The Bioko Island household database represents the backbone of all malaria interventions and, thus, has contributed greatly to the consolidation of a successful malaria control programme. The enumeration system proposed here, however, is far-reaching and can support virtually any household-level public health intervention. 


\section{Abbreviations}

BIMCP: Bioko Island Malaria Control Project; IRS: indoor residual spraying; LLINs: long-lasting insecticide-treated nets; MIS: malaria indicator survey; GPS: global positioning system; GIS: geographical information system; PDA: personal digital assistant; CIMS: Campaign Information Management System.

\section{Acknowledgements}

We thank the BIMCP mapping team who have sustained the mapping system throughout these years. We also thank the National Malaria Control Programme and the Ministry of Health and Social Welfare of Equatorial Guinea, as well as Marathon Oil, Noble Energy, AMPCO (Atlantic Methanol Production Company) and the Ministry of Mines and Energy of Equatorial Guinea for their continued support of this work.

\section{Authors' contributions}

GAG and CS conceptualized and supervised the mapping work. GAG, DEBH, JOON, JN, WPP, TS, GF and MP performed field activities. GAG, DEBH, MP and JS managed and cleaned the data sets. GAG and CAG performed the analyses, wrote the initial draft of the manuscript and prepared the figures and tables. All the authors read the initial draft and contributed with their feedback. All authors read and approved the final manuscript.

\section{Funding}

This work was funded by a private sector consortium led by Marathon Oil Corporation and the Government of Equatorial Guinea. The funders had no role in study design, analysis, decision to publish, or preparation of the manuscript.

\section{Availability of data and materials}

Data sharing not applicable to this article as it mainly explains methodological approaches to housing and household mapping and limited descriptive analyses of housing and household distribution are presented as illustrative examples of the mapping system.

\section{Ethics approval and consent to participate}

The housing and household mapping work was approved by the ethics committee of the Ministry of Health and Social Welfare of Equatorial Guinea.

\section{Consent for publication}

Not applicable.

\section{Competing interests}

The authors declare that they have no competing interests.

\section{Author details}

${ }^{1}$ Medical Care Development International, Silver Spring, MD, USA. ${ }^{2}$ Department of Epidemiology, University of Washington, Seattle, WA, USA. ${ }^{3}$ Medical Care Development International, Malabo, Equatorial Guinea. ${ }^{4}$ Sanaria Inc., Rockville, MD, USA. ${ }^{5}$ Equatorial Guinea Ministry of Health and Social Welfare, Malabo, Equatorial Guinea. ${ }^{6}$ London School of Hygiene and Tropical Medicine, London, UK. ${ }^{7}$ Medical Care Development, Inc., Augusta, ME, USA.

Received: 25 March 2019 Accepted: 17 August 2019

Published online: 22 August 2019

\section{References}

1. Kleinschmidt I, Torrez M, Schwabe C, Benavente L, Seocharan I, Jituboh $D$, et al. Factors influencing the effectiveness of malaria control in Bioko Island, Equatorial Guinea. Am J Trop Med Hyg. 2007;76:1027-32.

2. Kleinschmidt I, Sharp B, Benavente LE, Schwabe C, Torrez M, Kuklinski J, et al. Reduction in infection with Plasmodium falciparum one year after the introduction of malaria control interventions on Bioko Island, Equatorial Guinea. Am J Trop Med Hyg. 2006;74:972-8.

3. Bradley J, Monti F, Rehman AM, Schwabe C, Vargas D, Garcia G, et al. Infection importation: a key challenge to malaria elimination on Bioko Island, Equatorial Guinea. Malar J. 2015;14:46.
4. The Government of Equatorial Guinea, Medical Care Development International (MCDI). Bioko Island Malaria Control Project (BIMCP) \& Equatorial Guinea Malaria Vaccine Initiative (EGMVI) 4th Quarter Progress Report and Annual Review. Medical Care Development International; 2015

5. Cook J, Hergott D, Phiri W, Rivas MR, Bradley J, Segura L, et al. Trends in parasite prevalence following13 years of malaria interventions on Bioko island, Equatorial Guinea: 2004-2016. Malaria J. 2018;17:62.

6. Pardo G, Descalzo MA, Molina L, Custodio E, Lwanga M, Mangue C, et al. Impact of different strategies to control Plasmodium infection and anemia on the island of Bioko (Equatorial Guinea). Malar J. 2006;5:10.

7. Kleinschmidt I, Schwabe C, Benavente L, Torrez M, Ridl FC, Segura JL, et al. Marked increase in child survival after four years of intensive malaria control. Am J Trop Med Hyg. 2009;80:882-8.

8. Bradley J, Lines J, Fuseini G, Schwabe C, Monti F, Slotman M, et al. Outdoor biting by Anopheles mosquitoes on Bioko Island does not currently impact on malaria control. Malar J. 2015;14:170.

9. Sharp BL, Ridl FC, Govender D, Kuklinski J, Kleinschmidt I. Malaria vector control by indoor residual insecticide spraying on the tropical island of Bioko, Equatorial Guinea. Malar J. 2007;6:52.

10. Guerra CA, Kang SY, Citron DT, Hergott DEB, Perry M, Smith J, et al. Human mobility patterns and malaria importation on Bioko Island. Nat Commun. 2019;10(2332):11.

11. The Government of Equatorial Guinea, Medical Care Development International (MCDI). The Bioko Island Malaria Control Project Malaria Indicator Survey (MIS) 2017. Silver Spring: Medical Care Development International; 2017.

12. The Government of Equatorial Guinea, Medical Care Development International (MCDI). Bioko Island malaria control project (BIMCP) \& Equatorial Guinea Malaria Vaccine Initiative (EGMVI) Quarterly Progress Report_July-September 2017. Silver Spring: Medical Care Development International; 2017.

13. WHO. An operational manual for indoor residual spraying (IRS) for malaria transmission control and elimination. Geneva: World Health Organization 2015.

14. ICF International. Demographic and health survey sampling and household listing manual. Calverton: MEASURE DHS; 2012. p. 15.

15. Robertson M, Gogue C, Tynuv K, Wagman J, Ashley T, Larsen DA, et al. Challenges in measuring and analyzing vector control interventions: indicators, baselines and definitions. Massachusetts: IVCC, PMI, Abt Associates, PATH; 2017.

16. Kamanga A, Renn S, Pollard D, Bridges DJ, Chirwa B, Pinchoff J, et al. Open-source satellite enumeration to map households: planning and targeting indoor residual spraying for malaria. Malar J. 2015;14:345.

17. Pinchoff J, Larsen DA, Renn S, Pollard D, Fornadel C, Maire M, et al. Targeting indoor residual spraying for malaria using epidemiological data: a case study of the Zambia experience. Malar J. 2016;15:11.

18. Digital Globe. Pleiades-1A \& Pleiades-1B sensors; 2017. p. 19.

19. Thomson DR, Shitole S, Shitole T, Sawant K, Subbaraman R, Bloom DE, et al. A system for household enumeration and re-identification in densely populated slums to facilitate community research, education, and advocacy. PLoS ONE. 2014;9:e93925.

20. Bradley J, Hergott D, Garcia G, Lines J, Cook J, Slotman MA, et al. A cluster randomized trial comparing deltamethrin and bendiocarb as insecticides for indoor residual spraying to control malaria on Bioko Island, Equatorial Guinea. Malar J. 2016:15:378.

21. Olotu A, Urbano V, Hamad A, Eka M, Chemba M, Nyakarungu E, et al. Advancing global health through development and clinical trials partnerships: a randomized, placebo-controlled, double-blind assessment of safety, tolerability, and immunogenicity of PfSPZ vaccine for malaria in healthy Equatoguinean Men. Am J Trop Med Hyg. 2018;98:308-18.

22. The Government of Equatorial Guinea, Medical Care Development International (MCDI). The Bioko Island malaria control project population census. Malabo: The Government of Equatorial Guinea; 2015.

23. The Government of Equatorial Guinea, Medical Care Development International (MCDI). The Bioko Island malaria control project population census. Malabo: The Government of Equatorial Guinea; 2017.

24. Thomson DR, Stevens FR, Ruktanonchai NW, Tatem AJ, Castro MC. Grid Sample: an R package to generate household survey primary sampling units (PSUs) from gridded population data. Int J Health Geogr. 2017;16:25 
25. Murphy P. An overview of primary sampling units (PSUs) in multi-stage samples for demographic surveys. In: Proceedings of the American Statistical Association, Government Statistics Section; 2008. p. 2856-62

26. Sankoh O, INDEPTH Network and Partners. Why population-based data are crucial to achieving the sustainable development goals. Int J Epidemiol. 2017;46:4-7.

\section{Publisher's Note}

Springer Nature remains neutral with regard to jurisdictional claims in published maps and institutional affiliations.
Ready to submit your research? Choose BMC and benefit from:

- fast, convenient online submission

- thorough peer review by experienced researchers in your field

- rapid publication on acceptance

- support for research data, including large and complex data types

- gold Open Access which fosters wider collaboration and increased citations

- maximum visibility for your research: over 100M website views per year

At BMC, research is always in progress.

Learn more biomedcentral.com/submissions 